\title{
Capacitação para educadores de abrigo de crianças e adolescentes: identificando representações sociais
}

\section{Training for educators of children and teens shelter: identifying social representations}

\section{Capacitación para educadores de ninõs y adolescentes refugios:identificar las representaciones sociales}

\section{Nilma Soares Barros*}

Universidade Federal Rural do Rio de Janeiro - UFRRJ, Seropédica, Rio de Janeiro, Brasil

\section{Luciene Alves Miguez Naiff**}

Universidade Federal Rural do Rio de Janeiro - UFRRJ, Seropédica, Rio de Janeiro, Brasil

\begin{abstract}
RESUMO
Este estudo teve como principal objetivo identificar as representações sociais que educadores de abrigos para crianças e adolescentes fazem sobre a capacitação. A capacitação é um fenômeno do cotidiano dos abrigos e prevista nas legislações da área. No entanto, capacitar é uma forma de qualificação dos educadores que é oferecida de variadas maneiras, muitas vezes, descontextualizadas das principais demandas oriundas da práxis. Utilizamos como técnica de coleta um questionário acrescido de uma tarefa de associação livre com a palavra indutora "capacitação" que suscitou cognemas diretamente relacionados ao tema proposto. Foram registradas também informações oriundas da inserção no campo em forma de Diário de Campo. A análise das evocações foi feita pelo EVOC 2003® (Ensemble de programmes permettant l'analyse des evocations) e apontou como provável núcleo central, elementos como: aprendizado, aprimoramento, conhecimento e estudo. O diário de campo e a análise de conteúdo aprofundaram o estudo sugerindo representações sociais positivas sobre a capacitação na formação do profissional. Entretanto, indicaram que os educadores esperam que essa possa funcionar como um espaço de troca profissional e como suporte para instrumentalizá-los nas intervenções cotidianas.
\end{abstract}

Palavras-chave: representações sociais, capacitação / treinamento, educadores sociais.

\footnotetext{
ABSTRACT

This study aimed to identify the social representations that educators shelters for children and teens do about the training. The training is an everyday phenomenon in shelters provided for in the laws of the area. However, training is a form of qualification of educators that is offered in a variety of ways and often decontextualized of the major demands coming
} 
from the praxis. In this sense, we seek the social representations theory for understanding how educators have produced the consensual knowledge about the training. We use a task of free association with the word "capacity" which raised cognemas directly related to the proposed questionnaire. We also analyse information from the field in the form of field diary. Analysing the replies with the EVOC $\AA$ 2003. Ensemble de programs permettant I' analyze des evocations) was pointed as probable core elements: learning, improvement, knowledge and study. The field diary and content analysis deepened the study suggesting positive social representations on professional training. However, also indicated that educators hope that this could function as a space professional trading and support them in everyday interventions.

Keywords: social representations, qualification / training, educators.

\begin{abstract}
RESUMEN
Este estudio tuvo como objetivo identificar las representaciones sociales que los educadores de acogida para niños y adolescentes lo hacen en la formación. La formación es un fenómeno cotidiano y refugios previstos en las leyes de la zona. Sin embargo, la capacitación es una forma de calificación de los educadores que se ofrece en una variedad de formas y, a menudo descontextualizadas principales demandas provenientes de la praxis. Utilizamos como una técnica de muestreo mejorada de una tarea de libre asociación con la palabra inducir "empoderamiento", que levantó cognemas directamente relacionadas con el cuestionario tema propuesto. Fueron insertar información desde el terreno en forma de diario de campo también informó. El análisis de las respuestas fue tomada por EVOC ® 2003 (Ensemble programas De permettant l'analizan des evocaciones) y señaló como elementos centrales probables como: el aprendizaje, la mejora, el conocimiento y el estudio. El análisis diario de campo y el contenido se profundizó el estudio sugiere representaciones sociales positivas en la formación en la formación profesional. Sin embargo, indicaron que los educadores esperan que este puede funcionar como un profesional de comercio espacial y cómo apoyarlos en todos los días instrumentalizar las intervenciones.
\end{abstract}

Palabras clave: representaciones sociales, capacitación / formación, educadores.

\title{
1 Introdução
}

A Lei Federal 8069/90 de 13 de julho que instituiu o Estatuto da Criança e do Adolescente foi responsável por mudanças na concepção de infância e adolescência no Brasil. As mudanças, que tem como eixo central a ideia de que as crianças e os adolescentes são sujeitos de direitos, redimensionaram todo o atendimento oferecido até então. A família, a escola, a saúde, a assistência social e jurídica que incidiam sobre esses indivíduos passaram a obedecer ao princípio maior de proteção e garantia de direitos.

Nesse sentido, as diretrizes nacionais que norteiam a Política para Infância e Adolescência apontam para diversas ações de reordenamento das instâncias operadoras de direitos para adequação ao Estatuto da Criança e do Adolescente também conhecido pelas 
siglas ECRIAD ou ECA. Uma dessas ações foi reordenamento das instituições que atuavam com esse público-alvo em regime de internação, os chamados abrigos que passaram, dentre outras mudanças, a ter que respeitar a excepcionalidade e provisoriedade do atendimento institucionalizado, não separar irmãos, atender números pequenos de crianças e adolescentes, promover a reinserção familiar, dentre outras recomendações, em consonância com o Estatuto e com as políticas da assistência em vigência.

Um dos principais focos de atuação no processo de reordenamento dos antigos abrigos foram as capacitações, oferecidas como aulas, oficinas, palestras e outros dispositivos que pudessem colocar os profissionais atuantes nos abrigos a par das legislações que regulamentavam sua prática.

Após o ECA, foram elaboradas as diretrizes técnicas pelo CONANDAConselho Nacional dos Direitos da Criança e do Adolescente e pelo CNAS - Conselho Nacional de Assistência Social em 2009 que tiveram como objetivo a ordenação das ações em diferentes modalidades de acolhimento, nomenclatura inaugurada para tratar das medidas de proteção previstas no Estatuto. Abrigo, nessa nova nomenclatura passa a se chamar acolhimento institucional e passa a ter uma função de assegurar todos os direitos e não apenas a proteção física (Naiff, 2008; Rizzini, Rizzini, Naiff, \& Batista, 2007). Ambos os documentos seguiram as diretrizes propostas pelo Plano Nacional de Convivência Familiar e Comunitária- PNCFC (Brasil, Conselho Nacional dos Direitos da Criança e do Adolescente - CONANDA; Conselho Nacional de Assistência Social - CNAS; Secretaria Especial dos Direitos Humanos SEDH; Ministério do Desenvolvimento Social e Combate À Fome MDS, 2006) e pelo Sistema Único de Assistência Social-SUAS (NOB/SUAS, 2005).

Acompanhamos, desse modo, nos últimos 20 anos diversas mudanças na concepção da modalidade de proteção chamada abrigo, desde a reordenação resultante da implementação do ECA à sua inclusão de forma articulada com a política de assistência social (SUAS).

É grande a falta de consenso do que deve ser oferecido em forma de capacitação aos profissionais. Apesar de constar nos documentos regulatórios sugestões de temas para serem trabalhados, não há uma conceituação única sobre 0 que se entende por capacitação e formação continuada. Conforme apontado em Romans, Petrus, e Trilla, 2003, p. 124 "o educador social precisa de uma série de competências que irá desenvolvendo no desempenho do trabalho que a instituição contratante Ihe encomende". Tampouco o papel de educador social está totalmente delimitado e regulamentado conforme indicado no documento que atualmente regulamenta a profissão (Projeto de Lei 5346/2009). 
Nesse sentido, pensar o educador e a capacitação impõe uma visão ainda fragmentada nos significados, mas que ganha sentido na prática cotidiana. A Teoria das Representações Sociais é de grande valia na identificação do saber socialmente compartilhado pelos educadores sobre a capacitação já que advoga que é através da troca e consensuação de significados pelos grupos sociais que transformamos fenômenos antes não familiares ou estranhos em objetos de representações sociais cognoscíveis. (Moscovici, 2003; Jodelet, 2011).

Além do exposto acima, os estudos sobre capacitação no âmbito da Teoria das representações sociais são inexistentes, em especial se tratando de educadores sociais, caracterizando a relevância do presente estudo.

\section{Educadores sociais e capacitação}

No Brasil, a educação social surge na década de 1980 quando movimentos sociais lutavam pela não institucionalização e segregação de crianças e adolescentes. As intervenções vinham na contramão das ações disciplinadoras vigentes nessas instituições (Cunha, 2011). Dessa forma, entra em pauta uma nova categoria profissional, 0 educador social que constrói sua identidade "nos encontros, conflitos, trocas e entrechoques com diferentes áreas do saber" (Garcia \& Rota, 2011 , p. 61). O educador social pode receber influência de diferentes áreas de formação formal ou não formal. Além disso, pode ter vivenciado diferentes formas de atuação profissional. A existência da profissão "educador social" e sua respectiva valorização ainda estão em construção. O Projeto de Lei 5346/2009 que regulamenta a profissão tramita na Câmara dos Deputados (autor Chico Lopes, PC do B Ceará).

Pela Classificação Brasileira de Ocupação, criada com a Portaria no $397 / 02$ de 09 de outubro, o educador social se caracteriza como trabalhadores de atenção, defesa e proteção a pessoas em situação de risco e adolescentes em conflito com a lei.

Em relação ao educador/cuidador o perfil mínimo exigido para o exercício dessa função é a formação de ensino médio disponibilidade para atuar em cuidados básicos de crianças e adolescentes, assim como do ambiente em que eles estão, auxílio no atendimento voltado a resgate de autoestima cidadania e história de vida das crianças e adolescentes, dentre outros (Brasil, Ministério do Desenvolvimento Social - MDS, Secretaria Especial dos Direitos Humanos - SED, Conselho Nacional dos Direitos da Criança e do Adolescente CONANDA, Conselho Nacional de Assistência Social - CNAS, 2009).

Os educadores têm como responsabilidade desenvolver ações socioeducativas com grupo de crianças e adolescentes que estão 
acolhidos em abrigos institucionais. Sua atuação está inscrita em uma modalidade não formal de educação, que segundo Costa (2011) pode apresentar a seguinte compreensão: "atividade socioeducativa que, de forma continuada, visa à melhoria da vida da população, por meio de implementação de ações direcionadas para as necessidades básicas, e ao desenvolvimento de competências de um determinado grupo" (p.187).

Guará (2010) considerando como meta do trabalho dos abrigos a reintegração familiar, assinalou que os educadores devem também se apropriar do ECA (Lei Federal 8.069/90 de 13 de julho) no que tange a excepcionalidade e provisoriedade da atuação do abrigo na vida da criança para direcionar sua prática. Nesse caminho, não podem deixar de lado o que a autora denominou de "ações impostergáveis" como respeitar a individualidade de crianças e adolescentes e apoiálos quando necessário no decorrer do seu desenvolvimento integral.

Gulassa (2010) argumenta que o afeto do educador deve se dar de forma que promova a autonomia da criança e do adolescente e não alimentar uma dependência. A autora destaca ainda uma discussão muito comum nos abrigos que é comparar os cuidados do abrigo com os cuidados ofertados pelas famílias. O abrigo e seus profissionais não devem jamais pretender competir com a família. Seu lugar é preservar os direitos das crianças e adolescentes entendendo que esses precisarão de um ambiente familiar e comunitário para seu pleno desenvolvimento.

Tais aspectos só realçam a importância de cuidados com o educador social, pois como assinalou Gulassa (2010), o lugar do abrigo costuma ser um lugar de solidão. Nesse sentido, a autora advoga pela importância da capacitação como lócus de acolhimento de demandas dos educadores. E a contrapartida dessa situação é que a instituição precisa sair dessa posição atuando em Rede ${ }^{1}$.

Constatamos a pouca representatividade de pesquisas que abordem essa temática. Entretanto, vale destacar, alguns estudos (Orionte \& Souza, 2005; Nascimento, Lacaz, \& Travassos, 2010; Magalhães, Costa, \& Cavalcante, 2011) que apontam para a crescente importância que o tema capacitação passou a ter para os trabalhadores de abrigo, de como a atuação tem ficado cada vez mais técnica e da importância de "cuidar do cuidador", ou seja, de se aprimorar os níveis de atenção a esse profissional que lida com questões tão complexas e delicadas.

Apesar da falta de critérios acerca de como a capacitação deve acontecer, as Orientações Técnicas para os Serviços de Acolhimento (Brasil, Ministério do Desenvolvimento Social - MDS, Secretaria Especial dos Direitos Humanos - SED, Conselho Nacional dos Direitos da Criança e do Adolescente - CONANDA, Conselho Nacional de Ssistência Social - CNAS, 2009 listam alguns temas a serem abordados: "a) cuidados com crianças e adolescentes; b) noções 
sobre desenvolvimento infanto-juvenil; c) noções sobre ECA (Lei Federal 8.069/90 de 13 de julho) e SUAS (NOB/SUAS,2005) d) Sistema de Justiça e PNCFC" (Brasil, Conselho Nacional dos Direitos da Criança e do Adolescente - CONANDA; Conselho Nacional de Assistência Social - CNAS; Secretaria Especial dos Direitos Humanos SEDH ; Ministério do Desenvolvimento Social e Combate À Fome MDS, 2006, p.57). São temáticas direcionadas a adequação da prática profissional aos preceitos contidos nos documentos oficiais. Mas, não vemos nessas sugestões aspectos enfrentados no cotidiano do profissional educador social.

Um dos conceitos que encontramos na literatura e pode ajudar a entender a capacitação e pelo qual optamos é a perspectiva proposta por Carvalho e Nascimento (2002) que propõe pensar a capacitação dos profissionais dos abrigos como de Treinamento, Formação e Desenvolvimento, como é visto na área da psicologia organizacional. Compreende, segundo Felippe (2006), três categorias: formação, onde são oferecidas condições mínimas para o cargo; aperfeiçoamento, que visa a melhora na realização da função exercida; e desenvolvimento para trabalhar potencialidades, para assumir cargos no futuro. Vargas e Abbad (2006) sinalizaram para controvérsia existente entre as definições dos termos treinamento, desenvolvimento e educação, no entanto, reforçam que todos são processos de aprendizagem e visam mudanças de comportamento.

Já Petrus (2003) referindo-se especificamente aos educadores sociais, considerou que esses profissionais devem participar continuamente de formação que considerem, a princípio, duas aprendizagens: uma voltada para a melhoria das habilidades do próprio educador, e a segunda, a condição do educador auxiliar na melhora das habilidades a partir da interação com outro. As expressões treinamento e capacitação são reafirmadas nas publicações pesquisadas como estratégias de aprendizagem.

Diante de toda essa premente necessidade por capacitar educadores e ao mesmo tempo uma falta de critérios e avaliação de demandas é que percebemos a importância do presente estudo. Essa é uma temática privilegiada para se identificar as representações sociais circulantes entre os educadores sociais de abrigo de crianças e adolescentes já que encontramos sua emergência no grupo a ser pesquisado enquanto um objeto de produção de representações sociais.

\section{Representações sociais}

A Teoria das Representações Sociais a qual nos referimos foi publicada pela primeira vez pelo psicólogo social Serge Moscovici em 1961 com sua obra seminal intitulada: La Psicanalise son image et 
son public. A perspectiva do estudo das representações sociais possibilita uma aproximação com o funcionamento do pensamento social e com as identificações que os sujeitos/grupos possuem, e como, a partir desse processo, organizam seus comportamentos (Sá, 2004).

Moscovici (2003) argumenta que na tentativa de apreensão de fenômenos oriundos do universo reificado, ou seja, fenômenos tratados pela ciência, os indivíduos produzam um conhecimento conseusuado e de senso comum que seja mais facilmente apreendido pelos grupos respeitando suas especificidades. Nesse sentido, segundo o autor, produzir representações sociais é passar o conhecimento do universo reificado para o universo consensual.

A Teoria das Representações Sociais torna-se, nesse sentido, um fundamento essencial para se entender como fenômenos sociais são apropriados por grupamentos humanos que interagem entre si, levando em consideração que a dimensão social do indivíduo é determinante em seu comportamento e visão de mundo, ao mesmo tempo que esse indivíduo não é passivo e sim um ator social que nesse mesmo mundo interage e interfere (Moscovici, 2003; 2011; 2012).

Sendo assim, seguindo o que preconiza a Teoria das Representações Sociais (TRS), partimos do princípio de que sendo a capacitação uma obrigatoriedade nos abrigos; e que por isso interfira na dinâmica profissional dos educadores, os quais precisam cumprir tal exigência; e ao mesmo tempo ser uma prática que ainda carece de uma definição ou direcionamento que de fato permita aos atores envolvidos saberem os objetivos a serem atingidos; ela gere uma legítima tentativa de apropriação dos sentidos e significados, os quais possam transformá-la em algo cognoscível e familiar.

Ao longo de mais de 50 anos da Teoria das Representações Sociais, diversas contribuições somaram-se à versão apresentada por Serge Moscovici. As três mais importantes, que de acordo com Sá (1996), complementam a Teoria, podem ser descritas como: a abordagem Societal de Williem Doise; a abordagem proposta por Denise Jodelet que propõe uma aproximação com as práticas sociais; e a abordagem Estrutural de Jean Claude Abric. Deteremos-nos na abordagem estrutural por ter sido essa a escolhida no trato do presente estudo.

A Abordagem Estrutural incorpora uma teorização acerca de como se configuram os elementos das representações sociais. Essa abordagem ficou conhecida como Teoria do Núcleo Central. O conceito de representação social é compreendido por Abric (1994), da seguinte forma: "produto e processo de uma atividade mental pela qual um indivíduo ou grupo reconstitui o real com que se confronta e Ihe atribui uma significação específica" (p.13). Segundo o autor toda representação está organizada em torno de um Núcleo Central e será 
conhecendo o núcleo central que chegaremos ao verdadeiro sentido dado ao fenômeno pelo grupo.

As duas funções atribuídas ao Núcleo central são: a função geradora e a função organizadora. A primeira dá-se pela criação de elementos que são transformados e recebem significação a partir do Núcleo Central. E a segunda faz referência ao fato de o Núcleo determinar a natureza dos elementos que compõem a representação social, unificando-a e estabilizando-a. O Núcleo apresenta como propriedade principal a estabilidade.

Outro ponto importante da teoria de Abric é a compreensão dos elementos periféricos e suas respectivas funções. Estes estão em relação direta com o núcleo e terão, portanto, valor e função a partir dele. O sistema periférico tem seus elementos dispostos de forma hierarquizada. Quanto mais próximos do núcleo, mais são importantes na significação da representação, e se mais afastados apresentam outros aspectos ligados a sua significação. Sua importância justificar-se-á por "constituir a interface entre o núcleo central e a situação concreta na qual a representação é elaborada ou funciona e respondem a três funções essenciais": a) A primeira diz respeito a ação de tornar concreto o objeto representado; b) a segunda é a função de regulação e c) a terceira é a de defesa (Abric, 1994, p.23).

Conhecer os elementos presentes nas representações sociais que os educadores apresentam sobre capacitação auxilia-nos na compreensão do sentido atribuído por eles a esse fenômeno, bem como baliza a discussão sobre a relação dessas com a prática profissional no cotidiano do abrigo.

\section{Método}

\subsection{Participantes}

Participaram da pesquisa 100 educadores sociais que desenvolvem trabalhos nos Programas de Acolhimento Institucional em serviços públicos. Foram elegíveis para a amostra os profissionais que obedeciam aos seguintes critérios de corte: 1 ) Educadores que atuam em Municípios de grande porte ( 101.000 habitantes até 900.000 habitantes) onde, conforme preconizado na Norma Operacional Básica - Sistema Único da Assistência Social NOB - SUAS, deva oferecer serviços da proteção especial nos níveis de média e alta complexidade, incluindo abrigo. Dessa forma, abarcamos instituições em que a capacitação acontece obrigatoriamente nos abrigos segundo a NOB-SUAS. 2) Educadores que já receberam capacitação com base na suposição de que teriam uma aproximação com o tema em questão e estejam trabalhando atualmente no abrigo. 
Em relação à ocupação no abrigo, $84 \%$ do total dos participantes se definem com sendo educadores. Outros $16 \%$ correspondem aos supervisores de educadores e aos auxiliares de cuidadores, sendo estes últimos responsáveis pela limpeza do local. Esta última parcela citada, formada pelos supervisores e auxiliares, apareceu nos dados como "outros", mas para fins desta pesquisa todos foram nomeados educadores já que exerciam tal função nos abrigos.

Quanto ao sexo, a maioria dos educadores são mulheres, com o índice de $69,7 \%$, enquanto o sexo masculino é formado por 30,3\%. A maioria possui escolaridade de nível médio, $56 \%$.

\subsection{Procedimentos e instrumentos}

$\mathrm{Na}$ pesquisa empírica, para o levantamento das representações sociais, foi utilizado um questionário com perguntas abertas combinadas com a técnica de associação livre que permitiram o aparecimento de elementos de conexão de sentidos e significados. A tarefa de evocação livre permite a apreensão dos elementos cognitivos que possuem similitude e conexidade com o termo indutor e objeto de estudo da presente pesquisa. A combinação com perguntas abertas permite o aprofundamento dos significados, ou seja, a definição linguística assim como o sentido que é vinculado ao contexto do qual se fala. As perguntas fechadas foram para caracterização dos sujeitos, conforme apresentamos acima. Utilizamos ainda o Diário de campo em que foram registradas algumas passagens do cotidiano do abrigo que ficaram em evidência, revelando, nesse sentido, as próprias implicações e inquietudes da pesquisadora, conforme recomenda Lourau (1993).

Foram aplicados 100 questionários, para a análise dos dados foram utilizados 98, tendo em vista que dois foram anulados por apresentarem dados de difícil compreensão e por não estarem preenchidos totalmente.

A análise dos dados foi condizente com os instrumentos utilizados, a saber: software EVOC para as tarefas de evocação livre e Análise de Contéudo de Bardin (1977) e quantificação para as perguntas abertas. As perguntas fechadas foram apenas descritas em relação ao número absoluto e porcentagem em relação ao total. Portanto, as associações livres, presentes na primeira parte do questionário, forneceram evocações por meio do termo indutor, capacitação, que foram analisadas pelo EVOC. Na segunda parte do questionário, as perguntas abertas geraram respostas que foram transformadas em categorias e subcategorias pela análise de conteúdo e quantificadas para a identificação do grau de consenso em relação ao grupo. Os dados sócio-demográficos foram apenas organizados em quantificações simples. 
Os resultados de ambos os instrumentos ainda foram complementados pelo que foi percebido durante as visitas a 5 abrigos e registrado em um diário de campo. No diário de campo, as anotações foram feitas logo após as visitas nos abrigos para a coleta dos questionários. Lourau (1993) afirma que os diários ajudam na interpretação das implicações do pesquisador, Minayo (2010) o vê como um instrumento de anotações referentes as "percepções, angústias, questionamentos e informações que não são obtidas através da utilização de outras técnicas" (p.63). Portanto, antes de ser um complemento ao levantamento das representações sociais, 0 diário de campo foi de valia a pesquisadora na tentativa de apreender o cotidiano que se revelava nas incursões aos abrigos.

Todos os participantes receberam o Termo de Consentimento Livre e Esclarecido (TCLE). Neste documento, constam as informações sobre a pesquisa, incluindo o contato da pesquisadora principal. Somente após a leitura e concordância dos participantes foi iniciada a pesquisa propriamente dita. O projeto foi aprovado pelo Comitê de Ética da Universidade Federal Rural do Rio de Janeiro de acordo com Resolução no 196 de 10 de outubro de 1996 que prevê normas para pesquisas com seres humanos.

\section{Resultados}

\subsection{Estrutura das representações sociais}

\begin{tabular}{|c|c|c|c|c|c|c|}
\hline \multirow{2}{*}{$\begin{array}{l}\text { Aprendizado } \\
\text { Conhecimento } \\
\text { Estudo } \\
\text { Aprimoramento }\end{array}$} & \multicolumn{4}{|c|}{ Ordem Média 3,0 } & \multirow[b]{2}{*}{$\begin{array}{l}12 \\
10\end{array}$} & \multirow[b]{2}{*}{$\begin{array}{l}3,500 \\
3,400\end{array}$} \\
\hline & $\begin{array}{r}41 \\
35 \\
12 \\
12\end{array}$ & $\begin{array}{r}1,951 \\
2,057 \\
2,167 \\
2,333\end{array}$ & \multicolumn{2}{|c|}{$\begin{array}{l}\text { Troca de ideia } \\
\text { Mbtivação }\end{array}$} & & \\
\hline \multicolumn{3}{|l|}{ Freq uênc ia $<10$} & & & & \\
\hline Renovaçào 9 & \multicolumn{2}{|c|}{2,222} & Informação & 9 & & 3,222 \\
\hline Preparaçào & \multicolumn{2}{|c|}{1,667} & Valorizaçào & 9 & & 4,111 \\
\hline Trabalhar em equip & \multicolumn{2}{|c|}{72,571} & Respeito & 6 & & 500 \\
\hline Melhorar $\quad 7$ & \multicolumn{2}{|c|}{1,857} & Capacidade & 5 & & 2,800 \\
\hline Aperfeiçoamento & \multicolumn{2}{|c|}{62,000} & Integração & 5 & & 3,200 \\
\hline Qualificar & \multicolumn{2}{|c|}{2,500} & Paciência & 4 & & 4,000 \\
\hline Orientação & \multicolumn{2}{|c|}{1,800} & & & & \\
\hline Atualização & \multicolumn{2}{|c|}{2,250} & & & & \\
\hline Habilitar & \multicolumn{2}{|c|}{2,000} & & & & \\
\hline
\end{tabular}

Figura 1. Quadro de quatro casas ao termo indutor "capacitação". Rio de Janeiro, 2013.

Os dados levantados nas evocações livres coletadas foram processados pelo software EVOC. O produto final fornecido pelo Programa é um corpus com várias palavras distribuídas em quadrantes de acordo com a frequência média e ordem das 
evocações que apareceram no conjunto das evocações. A disposição dos elementos nos quadrantes nos indica a estrutura das representações sociais nos sistemas central e periférico. (Pereira, 2005). Neste estudo, as palavras encontradas organizaram-se de acordo com o arranjo mostrado na tabela 1.

No primeiro quadrante do lado esquerdo encontram-se os elementos prováveis do Núcleo Central. Estes elementos são os mais prontamente evocados e mais significativos (Abric, 1998). Neste estudo, a palavra: Aprendizado apareceu 41 vezes associada ao termo indutor capacitação, vindo logo em seguida o vocábulo Conhecimento, que aparece com uma frequência de 35 vezes. Esses dois vocábulos também apresentam a ordem de evocação mais próxima de 1 em relação aos demais. No provável núcleo central, encontramos ainda, com frequência de 12 , os cognemas Aprimoramento e Estudo.

Os elementos do Núcleo Central fornecem pistas da organização e dão significado a Representação Social (Abric, 1994). Diante do que foi encontrado é possível pensar que os educadores fazem uma representação sobre capacitação coerente com a ideia disseminada nos documentos relacionados à Política da Assistência Social e da Criança e do Adolescente. Desde o ECA (Lei Federal 8069/90 de 13 de julho), do SUAS (NOB/SUAS, 2005) e de outras ações e iniciativas da sociedade civil e de órgão públicos.

A importância da capacitação vem sendo apregoada como fundamental aos trabalhadores dos abrigos. De acordo com dados estatísticos elaborados pelo Conselho Nacional do Ministério Público (CNMP, 2013), a capacitação atinge atualmente cerca de $58 \%$ dos serviços de acolhimento institucional. Isso significa que o educador está cada vez mais sendo capacitado e, com isso, entrando em contato com os documentos que legislam sobre sua prática.

Nesse sentido, a coerência encontrada entre como os educadores pensam capacitação e as diretrizes da política da infância e adolescência, fundamentam representações que possuem elementos de um universo reificado.

Podemos dizer também que o provável núcleo central tem uma valorização positiva no sentido de que elementos como conhecimento, aprendizagem, estudo e aprimoramento são socialmente valorizados em nossa cultura. No entanto, vale supor que para os educadores, o "modus operandis" desta capacitação deve se dar no sentido de que também seja uma oportunidade de troca de ideias e motivação, conforme pode ser visto no quadrante superior direito, referente aos vocábulos da primeira periferia. Essas aparições indicam que as capacitações não devem se limitar a uma normatização da profissão. Devem ser espaços de trocas de experiência e de cuidado e proteção dos próprios profissionais. 
Para Abric (1994), os elementos presentes na primeira periferia vão proteger o Núcleo Central, legitimando a representação que o individuo ou grupo tenha em relação ao objeto. Flament (2001) refere-se aos elementos periféricos à ideia de para-choques que protegem o núcleo central de uma realidade que a questiona. A primeira periferia ancora a realidade do grupo mostrada pela centralidade da representação.

As palavras encontradas sugerem um entendimento semelhante à ideia trazida por Elage, Goes, Fiks, e Gentile (2011) referente à proposta de formação para os educadores: "um espaço de encontro, troca e diálogo, onde os trabalhadores encontram a possibilidade de conhecer, esclarecer e se posicionar (p. 47)".

A zona de contraste, no quadrante inferior esquerdo, apesar de apresentar frequência menor, refere-se as palavras que foram prontamente evocadas ou consideradas importantes por um grupo menor de indivíduos (Pereira, 2005). No caso desta pesquisa, o seu conteúdo parece reforçar o sentido das palavras presentes no núcleo central (aprendizado, conhecimento, estudo, aprimoramento), uma vez que traz os vocábulos que, semanticamente, se complementam e se assemelham como habilitar, renovação, preparação, melhorar, aperfeiçoamento, qualificar, orientação, atualização e trabalhar em equipe.

$\mathrm{Na} 2^{\mathrm{a}}$ Periferia estão os elementos com frequência menor e ordem de evocação mais elevada e que estão mais distantes em relação aos elementos centrais. Mas, vale destacar que as palavras presentes neste quadrante podem estar sinalizando para outra concepção de capacitação relacionada a temas a serem tratados ou a espaço para queixas de situações presentes no ambiente de trabalho. A segunda periferia deflagrou as inquietações presentes entre o que se sabe sobre o fazer (presente nas legislações e regulamentações e que alimenta as capacitações) e o fazer propriamente dito (o cotidiano de um educador que muitas vezes não tem respeito, valorização, integração e que precisa de paciência). Nesse sentido, os termos Informação, Valorização, Respeito, Capacidade, Integração e Paciência parecem sinalizar para características que os educadores desejam para si e que seriam fundamentais para a sua prática.

Ampliando o olhar para o significado dado á capacitação

O material discursivo presente nas perguntas abertas relacionadas ao tema complementam as inferências oferecidas pela tarefa de evocação livre.

O corpus deste estudo foi composto por 362 Unidades de Registro classificadas de acordo com duas Classes Temáticas: Significado de Capacitação e Capacitação e Práxis. A segunda classe temática foi a mais pregnante nas respostas aparecendo $68,24 \%$ no corpus, contra $31,76 \%$ da classe relativa ao Significado da Capacitação, conforme tabela 1. 


\begin{tabular}{|c|c|c|c|c|}
\hline $\begin{array}{l}\text { CLASSE } \\
\text { TEMATICA }\end{array}$ & CATEGOKIAS & $f(0,6)$ & SUBCAIEGORIAS & $f(0,8)$ \\
\hline \multirow[t]{2}{*}{$\begin{array}{l}\text { SIGIIIICADO } \\
\text { CAPACITACAAO }\end{array}$} & $\begin{array}{l}\text { Aquixição de } \\
\text { Conbecimento }\end{array}$ & 17,95 & $\begin{array}{l}\text { Aprendirado } \\
\text { Aprinoranento }\end{array}$ & $\frac{11,32}{6,63}$ \\
\hline & Reflexioes & 13,81 & Troca & 13,81 \\
\hline \multirow{5}{*}{$\begin{array}{l}\text { CAPACTIACAOF } \\
\text { PRAXIS }\end{array}$} & \multirow{3}{*}{$\begin{array}{l}\text { Cotidiano do } \\
\text { abrigo }\end{array}$} & \multirow{3}{*}{33,7} & Contribuiçäo & 17,68 \\
\hline & & & $\begin{array}{l}\text { Relacionamento entre os } \\
\text { educadores e } \\
\text { criancas adolescentes }\end{array}$ & 12,15 \\
\hline & & & Trabatho en equipe & 3,87 \\
\hline & \multirow[t]{2}{*}{ Perspectir as } & \multirow{2}{*}{34,54} & Sugestâo de $\mathrm{T}$ em as & 31,23 \\
\hline & & & Criticas & 3,31 \\
\hline
\end{tabular}

Tabela 1: Configuração temática e categorial da análise de conteúdo.

Na primeira classe temática, denominada Significado de Capacitação, encontramos duas categorias que organizam o conteúdo levantado: a) Aquisição de conhecimento com $17,95 \%$ e b) reflexões com $13,81 \%$. A primeira categoria dessa temática se subdivide em duas sub-categorias: Aprendizagem e Aprimoramento. A segunda categoria apresenta apenas uma subcategoria que é Troca. Portanto, o conteúdo discursivo dessa primeira classe temática acompanha os achados do núcleo central e da primeira periferia e dão o tom de importância que os educadores atribuem à capacitação, realçando representações sociais que mostram como os elementos do universo reificado foram compreendidos e elaborados pelos educadores.

Nessa lógica, cabe ao espaço de capacitação ser um lugar de construção de metodologias participativas que vão auxiliar em suas atuações cotidianas, conforme destacado por Elage et al. (2011). Para esses autores, possibilitar a reflexão de educadores traz um aspecto de grande valor, pois contribui para uma sensibilização em relação ao público atendido, bem como para construção de intervenções com mais qualidade, favorecendo a dimensão educacional a partir das relações cotidianas entre educadores e criança/adolescente. A segunda Classe temática apresenta de forma inequívoca a relação existente entre capacitação e prática, aparecendo em $68,24 \%$ do córpus e traz nuances que parecem bem peculiar ao universo da atuação do educador, sinalizando para o modelo de capacitação que desenvolva habilidades específicas para o cotidiano.

O trabalho no abrigo faz do educador um cuidador que nem sempre é cuidado, ou seja, suas demandas nem sempre são respeitadas (Gulassa, 2010). As subcategorias relacionadas à categoria Cotidiano do abrigo realçaram essa dimensão da complexidade de seu trabalho e de como isso reflete na sua atuação do dia a dia. Foi destaque a Contribuição, o Relacionamento entre crianças e adolescentes e educadores e o Trabalho em Equipe. 
A relação entre educador e criança/adolescente tem sido destacada como sendo fundamental para um atendimento de qualidade. Essa relação deve estar pautada em segurança, acolhida e ser suportiva, tendo em vista que se trata de crianças/adolescentes que tiveram seus vínculos, com pessoas significativas, rompidos (Grajew, 2012). Elage et al. (2011) já sinalizaram o fato de que os educadores ocupam-se com suas tarefas rotineiras e não conseguiram compreender que a dimensão educativa desenvolve-se na relação.

A categoria Perspectiva tem a intenção de destacar a direção do olhar do educador, no que se refere ao que ele espera de um espaço de capacitação. Sugestões de Temas e Críticas formam as subcategorias. Das 362 unidades de registro, 120 (equivalente a $31,23 \%$ do total do corpus) compreendem a subcategoria Sugestões de temas. O que mostra sua pregnância nas falas dos sujeitos. Campos(2012) salientou: "Uma representação dá significado a uma dada situação social, bem como aos comportamentos e condutas observados" (p.16). A aproximação com a sugestão de temas sugeridos para capacitação facilita o entendimento do significado que os educadores Ihe atribuem. $O$ tipo de conteúdo que querem ver presentes em uma capacitação parecem ter sido elencados a partir das dificuldades encontradas em sua prática.

\subsection{Diário de campo}

Nessa etapa foram observados os seguintes itens: a) acolhida a pesquisa; b) condições dos abrigos; c) crianças e adolescentes; d) falas dos educadores; e) relacionamento entre profissionais e atendidos. Com exceção de um abrigo, a acolhida à pesquisa e à pesquisadora foi positiva. Os abrigos visitados, em sua maioria, chamaram a atenção pelas condições de sua infraestrutura. Funcionando em antigas construções e visivelmente sem manutenção e com recursos humanos também escassos, pareciam refletir 0 tratamento de pouca importância que as crianças e adolescentes têm recebido ao longo da história (Rizzini \& Rizzini, 2004; Rizzini, 2008; Faleiros, 2011; Daffre, 2012).

Capacitação, complexidade do cotidiano de abrigo, insatisfações com a política para crianças e adolescentes e queixas profissionais dos educadores foram as temáticas que permearam as discussões. Muitas vezes o tom da conversa foi de abandono, fosse da própria instituição, das crianças ou dos educadores. Esse aspecto foi trazido por Gulassa (2010) e por Andrade (2012) que sinalizaram para o abandono que é característica da demanda acolhida e que parece se repetir na instituição e em seus trabalhadores.

\section{Considerações finais}


Os modelos de acolhimento institucional ou abrigos abarcam um sistema complexo que envolve trabalho em rede, recursos financeiros e capacitação para seus trabalhadores. Essa complexidade faz com que o abrigo seja um órgão, que, para cumprir sua função de medida de proteção, deva ser visto como um serviço de qualidade. Nesse sentido, a capacitação e a formação continuada devem sempre ser tratadas como medidas de excelência no aprimoramento dos profissionais.

As representações sociais positivadas que os educadores apresentaram sobre capacitação sugerem que não há uma rejeição por esse tipo de treinamento no trabalho. No entanto, a forma como vem sendo oferecida ainda não contempla suas necessidades. Esse entendimento pode contribuir para a elaboração de metodologias de capacitação que, sem desrespeitar as sugestões advindas dos documentos governamentais e das publicações significativas da área, possam ratificar as demandas dos educadores.

Vimos nos documentos referentes à Política para a Infância e Adolescência a importância dada à capacitação, os prováveis elementos do Núcleo Central deste estudo confirmaram essa perspectiva. Nesse sentido, podemos inferir que os educadores estão absorvendo, em seu conhecimento socialmente compartilhado acerca da capacitação, elementos oriundos do discurso oficial circulante.

No entanto, o diálogo entre centralidade e periferia associado ao discurso coletado nas perguntas abertas revelou aspectos complementares a essa ideia mostrando que não basta apenas ressaltar a importância de se qualificar trabalhadores de abrigo. Os educadores parecem esperar que a capacitação possa ser um espaço de aprendizado que auxilie nas intervenções de uma forma mais específica e relacionada com o que conhecem sobre seu cotidiano. Ou seja, deve haver um diálogo entre o que se pretende ensinar e a ação executada, como salientou Nogueira (2012): "A formação se dá principalmente através de articulação entre teoria e prática" (p.69).

Outro aspecto que merece ser salientado diz respeito a função identitária da Representação Social, que define a identidade e situa o grupo em seu campo social (Abric, 1994). A identidade do educador social vai se constituindo pela práxis e pela interação entre o grupo. Hoje em dia a ocupação profissional de educador social ainda é muito frágil em termos de garantia de direitos trabalhistas já que a regulamentação da profissão ainda está em execução, portanto os dados mostram que os educadores tem expectativas que as capacitações também seja um espaço de fortalecimento desse aspecto. Assim, a capacitação cumpre com a função de preservar o que o grupo constituiu como identidade, e auxilia na proteção de suas especificidades. 
Acredita-se que investir na formação humana, como salientaram Orionte e Souza (2007), é investir na preparação de educadores como "construtores de subjetividade" para assim, aumentar a probabilidade de mudança significativa nos abrigos. Ou seja, ver os educadores como atores sociais que podem interferir diretamente na forma como irão existir enquanto categoria na sociedade, repensando com isso seu papel e compromisso social.

Em suma, podemos considerar que os educadores conhecem 0 significado mais amplo sobre capacitação, e demandam por uma capacitação que responda aos anseios de sua prática. Aprimoramento e conhecimento devem atender ao que se espera que o educador apresente no trabalho com as crianças e adolescentes. A capacitação não deve ser executada como uma obrigação legal apenas, deve poder agir nas especificidades e complexidade que esse tipo de atendimento requer.

Dessa forma pretendemos mostrar como esses educadores são hoje alvo de inúmeras intervenções de cunho educativo, informativo e de formação no sentido de melhorar sua atuação, mas que ao mesmo tempo, essas ações ainda se encontram desarticuladas e refletem a não regulamentação profissional desta categoria. Ouvir os educadores e suas representações sociais amplia o debate acerca do que se espera dos acolhimentos institucionais pós-ECA e mostra que de nada adianta pensar no cuidado às crianças e adolescentes submetidos a essa medida de proteção sem pensar em cuidar do cuidador. É nesse sentido, que Gulassa (2010), defende a ideia de: "criar espaços próprios para o educador lidar com seus sentimentos, conflitos, amores e raivas" (p.31). Esse seria então, um caminho para cuidar do cuidador.

\section{Referências}

Abric, J. C. (1994). Praticas Socialis y Representaciones. México: Filosofia y Cultura Contemporânea.

Abric, J. C. (1998). A abordagem estrutural das representações sociais. In A.S.P. Moreira, \& D. C. Oliveira (Orgs.). Estudos interdisciplinares de representação social (pp. 27-38). Goiânia: $A B$.

Andrade, S. (2012). Histórias que não se Contam sobre o Desacolhimento de crianças: (Im) Possibilidades de discussão com o Poder Judiciário. In S.G. Daffre (Org.). A realidade dos Abrigos: Descaso ou Prioridade?(pp.110-135). São Paulo: Zagodoni Editora Ltda.

Bardin, L. (1977). Análise de conteúdo. Lisboa: Edições 70.

Brasil, Conselho Nacional dos Direitos da Criança e do Adolescente CONANDA; Conselho Nacional de Assistência Social - CNAS; 
Secretaria Especial dos Direitos Humanos - SEDH; Ministério do Desenvolvimento Social e Combate À Fome - MDS (2006). Plano Nacional de Convivência Familiar e Comunitária. Brasília DF: Autor.

Brasil, Ministério do Desenvolvimento Social - MDS, Secretaria Especial dos Direitos Humanos-SEDH, o Conselho Nacional dos Direitos da Criança e do Adolescente- CONANDA e o Conselho Nacional Assistência Social - CNAS (2009). Orientações Técnicas: Serviços de Acolhimento para Crianças e Adolescentes. Brasília - DF: Autor.

Campos, P.H.F. (2012). A abordagem Estrutural e o estudo das relações entre práticas e representações sociais. In P. H. F. Campos, P.H.F., \& S. Loureiro (Eds). Representações Sociais Práticas Educativas (pp. 22-36). Goiânia: Ed. UFG.

Carvalho, A. V. de, \& Nascimento, L. P. do. (2002). Administração de Recursos Humanos. São Paulo: Pioneira.

CNMP - Conselho Nacional do Ministério Público (2011). Resolução no 71, de 15 de Junho de 2011.

Costa, C. R da (2011). A importância da Educação não formal nas políticas públicas. Revista Ciência e Educação, 1(25), 179-194.

Cunha, R. de C. (jan-jul, 2011). O Educador Social e sua Inserção nas Políticas Públicas: imprescindibilidade ou rearranjo do capital? REDD - Revista Espaço de Diálogo e Desconexão, 3(2), 1-11. Recuperado em 18 de março, 2013 de http://seer.fclar.unesp.br/redd/article/view/4438

Daffre, S. G. (2012). A realidade dos Abrigos: Descaso ou Prioridade?. Zagodoni Editora: São Paulo.

Elage, B., Góes, M., Fiks, M., \& Gentile, R. (2011). Perspectivas formação de profissionais em serviços de acolhimento. São Paulo: Instituto Fazendo História.

Faleiros, T. S. (2011). A criança e o adolescente. Objetos sem valor no Brasil Colônia e no Império. In: I, Rizzini, \& F. Pilotti. A Arte de Governar Crianças. (pp. 203-222). Rio de Janeiro: Cortez.

Felippe, M. I. (2006). Identificação de necessidades de treinamento por competência. In Boog, G., \& Boog, M (Coords). Manual de Treinamento e Desenvolvimento - Processos e Operações. Associação Brasileira de Treinamento e Desenvolvimento (pp. 6-23). Pearson Education.

Flament, C. (2001). Estrutura e Dinâmica das Representações Sociais. In D. Jodelet (Org.). As Representações Sociais. (pp.173-200). Petrópolis, RJ: Vozes.

Garcia, V. A, \& Rotta, D. C. (2011). A importância da Educação não formal nas políticas públicas. Revista Ciência e Educação, (25), 53-70.

Grajew, O. (2012). Políticas Públicas e a garantia de um atendimento de qualidade nos abrigos. In S.G. Daffre (Org.). A realidade dos 
Abrigos: Descaso ou Prioridade?. (pp.136-151). São Paulo: Zagodoni Editora.

Guará, I. M. F. R. (2010). Abrigo - comunidade de acolhida e socioeducação. In M. V. Baptista, \& I. M. F. R. Guará (Coords.). Abrigo: comunidade de acolhida e socioeducação (2a $\mathrm{Ed}$., pp.59-72). São Paulo: NECA.

Gulassa, M. L. C. R. (2010). A fala dos Abrigos. In M. V. Baptista, \& I. M. F. R. Guará (Coord.). Abrigo: comunidade de acolhida e socioeducação (2a Ed, pp.49-58). São Paulo: NECA.

Jodelet, D. (2011). A fecundidade da obra "A psicanálise, sua imagem e seu público". In A. M. de O. Almeida, M. de F. S. Santos, \& Z. A. Trindade. Tema das Representações Sociais - 50 anos. (pp.199 -219). Brasilia: UNB, Co-edição com Centro Moscovici.

Lei Federal 8069/90 de 13 de julho. Dispõe sobre o Estatuto da Criança e do Adolescente e dá outras providências. Recuperado em 27 de novembro, 2012 de http://www.planalto.gov.br/ccivil_03/leis/L8069.htm

Lourau, R. (1993). Análise Institucional e prática de Pesquisa. Rio de Janeiro: Eduerj.

Magalhães, C. M. C., Costa, L. N., \& Cavalcante, L. I. C. (2011). Percepção de educadores de abrigo: O seu trabalho e a criança institucionalizada. Revista Brasileira de Crescimento Desenvolvimento Humano, 21(3), 818-831.

Martinho, C. \& Felix, C. (2011). Vida em Rede - Conexões, relacionamentos e caminhos para uma nova sociedade. São Paulo: Instituto C\&A.

Minayo, M. C. de S. (2010). Pesquisa social: teoria, método e criatividade. 29. ed. Petrópolis, RJ: Vozes.

Moscovici, S. (2003) Representações Sociais (4aed). Petrópolis, RJ: Vozes.

Moscovici, S. (2011). Prefácio: 50 anos da Teoria das Representações Sociais. Temas em Psicologia, 19(1), 1-2.

Moscovici, S. (2012) A psicanálise sua imagem e seu público. Petrópolis: Vozes (Trabalho Original Publicado em 1961).

Naiff, L. A. M. (2008). Acolhendo crianças e adolescentes da violência social. Boletim Interfaces da Psicologia, 1, 26-30.

Nascimento, M. L. do, Lacaz, A. S., \& Travassos, M. (2010). Descompassos entre a lei e o cotidiano nos abrigos: percursos do ECA. Canoas: Aletheia, 31. Recuperado em 09 de janeiro, 2012 em http://pepsic.bvsalud.org/scielo.php?script=sci_arttext\&pid=S1 413-03942010000100003\&lng = pt\&nrm =iso

NOB/SUAS (2005). Norma Operacional Básica/Sistema Único de Assistência Social. Ministério de Desenvolvimento Social e Combate a Fome - MDS. Conselho Nacional de Assistência Social. Brasília-DF: Autor. 
Nogueira, F. (2012). "A palavra do Bebê": a Importância da História de Vida no Acolhimento Institucional de Bebês e Mães Adolescentes: (Im) Possibilidades de Discussão com o Poder Judiciário. In S. G. Daffre (Org.). A realidade dos Abrigos: Descaso ou Prioridade? (pp. 64-79). São Paulo: Zagodini Editora Ltda.

Oriente, I. Sousa, \& S. M. G. (2005) O significado do abandono para crianças institucionalizadas. Psicologia em Revista, 11(17), 2946.

Pereira, F. J. C. (2005). Análise de dados qualitativos aplicados às Representações Sociais. In A. S. P. Moreira, B. V. Camargo, J. C. Jesuino, \& S. M. da Nóbrega (Orgs). Perspectivas Teórico Metodológicas em Representações Sociais. (pp. 25-60). João Pessoa: UFPB/Editora Universitária.

Petrus A. (2003). Novos âmbitos em Educação Social. In M. Romans, A. Petrus, \& J. Trilla (Orgs.). Profissão Educador Social. (pp. 115-200). Porto Alegre. Artmed.

Portaria no 397/02 de 09 de outubro. Classificação Brasileira de Ocupações. Acessado em 3 de junho, 2014, em http://www.mtecbo.gov.br/cbosite/pages/legislacao.jsf.

Projeto de Lei 05346/2009 (2009), de autoria do deputado federal Chico Lopes (PCdoB/CE), que dispõe sobre a criação da profissão de educador e educadora social e dá outras providências. Recuperado em 12 de fevereiro, 2013 de http://www.camara.gov.br/proposicoesWeb/prop_mostrarintegr a;jsessionid =E0B2645BB919DAD83A0D400EAB83C611. node1?c odteor $=661788 \&$ filename $=P L+5346 / 2009$

Rizzini. I, \& Rizzini, I (2004). A Institucionalização de crianças no Brasil: percursos históricos e desafios. Rio de Janeiro: Edições Loyola.

Rizzini, I., Rizzini, I., Naif, L., \& Batista, R. (2007). Acolhendo crianças e adolescentes. São Paulo: Ed.Cortez/ UNICEF.

Rizzini, I. (2008). O Século Perdido. Editora Cortez: Rio de Janeiro.

Romans, M., Petrus, A, \& Trilla, J. (2003). Profissão: educador social. Porto Alegre: Artmed.

Sá, C.P. (1996). Núcleo Central das Representações Sociais. Petrópolis: Vozes.

Sá, C.P. (2004). Representações Sociais: o conceito e o estado atual da teoria. In M. J. Spink (Org.) O Conhecimento do Cotidiano As Representações Sociais na Perspectiva da Psicologia Social. (pp. 125-147). São Paulo: Brasiliense.

Vargas, M. R. M., \& Abbad, G. S. (2006). Bases Conceituais em treinamento, desenvolvimento e educação. TD\&E. In J. E. Borges- Andrade, G. S. Abbad, \& L. Mourão (Orgs.). Treinamento, Desenvolvimento e Educação em Organizações e Trabalho. (pp. 137-158). Porto Alegre: Artmed. 


\section{Endereço para correspondência \\ Nilma Soares Barros}

Universidade Federal Rural do Rio de Janeiro

Departamento de Psicologia - Programa de pós-Graduação em Psicologia

Rodovia Km 65, Seropédica, RJ, Brasil

Endereço eletrônico: nilma_barros@yahoo.com.br

Luciene Alves Miguez Naiff

Universidade Federal Rural do Rio de Janeiro

Departamento de Psicologia - Programa de pós-graduação em Psicologia

Rodovia Km 65, Seropédica, RJ, Brasil

Endereço eletrônico: lunaiff@hotmail.com

Recebido em: $11 / 06 / 2014$

Reformulado em: 06/12/2014

Aceito para publicação em: 22/01/2015

\section{Notas}

* Mestre em Psicologia pelo Programa de Pós-graduação stricto sensu em psicologia da UFRRJ.

** Docente permanente do Programa de Pós-graduação stricto sensu em Psicologia da UFRRJ.

1 "A palavra 'rede' deriva do latim retis, que se refere a trama ou conjunto de fios entrelaçados. Associa a ideia de socius ou sociedade, a noção de rede irá designar o fenômeno de elaboração dos vínculos sociais entre indivíduos e grupo de indivíduos" (Martinho \& Felix, 2011, p. 13). 